\title{
Efficacy and safety of oxcarbazepine in the treatment of children with epilepsy: a meta- analysis of randomized controlled trials
}

This article was published in the following Dove Press journal:

Neuropsychiatric Disease and Treatment

2 March 2017

Number of times this article has been viewed

\section{Hua Geng \\ Chengzhong Wang}

Department of Pediatrics, Maternal and Child Health Hospital of Yancheng, Yancheng City, People's Republic of China
Correspondence: Chengzhong Wang Department of Pediatrics, Maternal and Child Health Hospital of Yancheng, Yancheng City, Jiangsu Province, 224002, People's Republic of China Email wangmengzh@sohu.com
Background: To assess the efficacy and safety of oxcarbazepine (OXC) in the treatment of children with epilepsy.

Methods: Randomized controlled trials (RCTs) published in PubMed, Embase, Web of Science, Cochrane Library, Scopus, SinoMed (Chinese BioMedical Literature Service System, China), and Chinese National Knowledge Infrastructure (China) database were systematically reviewed. Eligible studies were those that compared the efficacy and safety of OXC with other antiepileptic drugs in epilepsy. Risk ratio (RR) with $95 \%$ confidence intervals (95\% CIs) was calculated using fixed-effects or random-effects model.

Results: Eleven RCTs with a total of 1,241 patients met the inclusion criteria and were included in this meta-analysis. Compared with other antiepileptic drugs (sodium valproate, levetiracetam, phenytoin, and placebo), $\mathrm{OXC}$ was associated with similar seizure-free rate ( $\mathrm{RR}=1.06,95 \%$ CI: $0.94,1.20 ; P=0.366$ ) and percentage reduction from baseline in seizure frequency (for $\geq 75 \%$ reduction: $\mathrm{RR}=1.15,95 \% \mathrm{CI}: 0.88,1.49 ; P=0.310$; for $50 \%-75 \%$ reduction: $\mathrm{RR}=1.12,95 \% \mathrm{CI}$ : $0.90,1.39 ; P=0.301$; for $<50 \%$ reduction: $\mathrm{RR}=0.79,95 \% \mathrm{CI}: 0.56,1.12 ; P=0.179)$. Moreover, patients treated with OXC had a comparable incidence of adverse events compared with those treated with other antiepileptic drugs $(\mathrm{RR}=1.01,95 \% \mathrm{CI}$ : $0.92,1.11 ; P=0.760)$.

Conclusion: OXC showed similar effects and safety as other antiepileptic drugs in the treatment of children with epilepsy. Further well-conducted, large-scale RCTs are needed to validate these findings.

Keywords: epilepsy, children, oxcarbazepine, meta-analysis

\section{Introduction}

Epilepsy is a disease characterized by a wide range of symptoms resulting from a variety of cerebral disorders. ${ }^{1}$ Semiologically, it is classified as partial or generalized. ${ }^{2}$ The clinical manifestations can occur through sensitive, sensory, psychological, vegetative, and motor signs and symptoms of simple or complex nature depending on the neural system involved in the genesis of the disease..$^{2-4}$ It has been estimated that 50 million patients around the world suffer from epilepsy. ${ }^{1}$ Treatment approaches for pediatric population with epilepsy still face unique challenges. Despite seizures being effectively controlled by the antiepileptic drugs (AEDs) in most of children, more than $25 \%$ of pediatric patients who were treated with AEDs still developed intractable seizures or troublesome adverse events. ${ }^{5}$ In the past decade, new AEDs have been introduced, and these have proved to be effective and well-tolerated in patients.

Oxcarbazepine (OXC) is a new AED that is used for epilepsy treatment, both in adults and in pediatric patients..$^{6-8}$ It was developed in an attempt to improve the 
tolerability of carbamazepine without affecting its anticonvulsant potency. ${ }^{9}$ Having been registered in more than 50 countries around the world, OXC is widely used as first-line and add-on treatment for generalized tonic-clonic seizures (GTCS) and partial seizures with or without secondarily generalized seizures. ${ }^{10}$ Because OXC did not have the extensive oxidative metabolism, it had a lower potential for induction of hepatic enzymes than other AEDS. ${ }^{11}$ Moreover, owning to the low protein binding (40\%), OXC induced markedly fewer pharmacokinetic drug interactions and treatment-related adverse events than standard AEDs. ${ }^{10-12}$

The effects and safety of OXC have been evaluated in several clinical trials; however, their results remained controversial. Therefore, we conducted this meta-analysis based on eligible randomized controlled trials (RCTs) to compare the efficacy and safety of OXC with other AEDs in children with epilepsy.

\section{Methods and materials Search strategy}

The present meta-analysis was performed in accordance with the Preferred Reporting Items for Systematic Reviews and Meta-Analysis (PRISMA) statement guidelines. ${ }^{13}$ We conducted a systematic electronic search in PubMed, Embase, Web of Science, Cochrane Library, Scopus, SinoMed (Chinese BioMedical Literature Service System, China), and China National Knowledge Infrastructure (China) from inception to October 12, 2016, and the literature search was updated on January 12, 2017. The following search items were used: (("pediatrics" [MeSH Terms] OR "pediatrics" [All Fields] OR "pediatric" [All Fields]) OR ("Childhood" [Journal] OR “childhood" [All Fields])) AND (“epilepsy” [MeSH Terms] OR “epilepsy”[All Fields]) AND (“oxcarbazepine” [Supplementary Concept] OR “oxcarbazepine" [All Fields]). There was no language restriction, but participant ages were restricted to children aged between 3 and 17 years. We also manually searched the reference lists of relevant reviews and all included studies until no potentially eligible studies were found.

\section{Study selection}

Two investigators (Hua Geng and Chengzhong Wang) independently conducted the initial search, deleted duplicate records, reviewed the abstract/title and full-text information, and identified the records as included or excluded. The disagreement between two investigators was resolved by discussion and consensus. Studies included in this meta-analysis must meet the following selection criteria: 1) study design: RCTs; 2) population: involving children with epilepsy; 3) intervention: OXC; 4) comparison: other AEDs or placebo; and 5) outcomes: providing at least one of the following outcomes: seizure-free rate, reduction from baseline in seizure frequency, and adverse events.

\section{Data collection}

Data collection was performed by two independent investigators (Hua Geng and Chengzhong Wang). A standardized Excel form file was used to extract the following information from the included studies: first author's name, year of publication, country, number of patients in each group, patients' demographic characteristics, duration of the follow-up, dosage of OXC, and outcome data. We also contacted the corresponding authors for missing data.

\section{Risk of bias assessment and grading quality of evidence assessment}

We assessed the risk of bias in included studies, using the Cochrane risk of bias tool. ${ }^{14}$ Each trial was regarded as at being high, low, or unclear risk of bias according to the following criteria: random sequence generation, allocation concealment, blinding of outcome participants and personnel, blinding of outcome assessment, incomplete outcome data, selective reporting, and other bias.

The quality of evidence for outcomes was evaluated according to the Grading of Recommendations Assessment, Development, and Evaluation (GRADE) methodology ${ }^{15}$ and was classified as very low, low, moderate, or high. A summary table was prepared using the GRADE profiler (GRADE pro, version 3.6).

\section{Statistical analysis}

We calculated risk ratio (RR) with 95\% confidence intervals ( $95 \%$ CIs) for dichotomous outcomes. Heterogeneity across the included studies was assessed by using $I^{2}$ statistic and Cochran's $Q \chi^{2}$ test. ${ }^{16}$ An $I^{2}$ value $>50 \%$, or the value of $P<0.10$ indicated significant heterogeneity. ${ }^{16}$ When significant heterogeneity was identified, a random-effects model (DerSimonian-Laird method) ${ }^{17}$ was used to pool the estimates; otherwise, a fixed-effects model (Mantel-Haenszel method $)^{18}$ was applied. We also conducted subgroup analysis based on comparators, study quality, and sample size to check the influence of various factors on the outcomes. Publication bias was assessed using Begg's ${ }^{19}$ and Egger' ${ }^{20}$ tests. A $P$-value of $<0.05$ was considered as statistically significant, except where otherwise specified. All analyses were performed using STATA version 12.0 (Stata Corporation, College Station, TX, USA). 


\section{Results \\ Literature search}

The initial search yielded 2,911 records. Of these, 1,924 were removed as they were duplicate records and 966 were excluded after a review of titles/abstracts. Then, 21 potential studies were identified for further analysis. However, 10 of them were excluded for the following reasons: eight studies involved adults rather than children; one study did not provide outcome of our interest; and one study was a single-arm trial (Figure 1). Finally, $11 \mathrm{RCTs}^{21-31}$ met the inclusion criteria and were included in this meta-analysis.

\section{Study characteristics}

The main characteristics of the included studies are presented in Table 1. These RCTs were published from 1997 to 2016. The sample size in these studies ranged from 39 to 267. Among these RCTs, one was conducted in Brazil, ${ }^{21}$ one in the USA, ${ }^{22}$ one in Italy, ${ }^{23}$ and eight in China. ${ }^{24-31} \mathrm{Six}$ studies compared OXC with levetiracetam; ${ }^{23,25,28-31}$ three studies compared OXC with sodium valproate, ${ }^{24,26,27}$ each study compared OXC with phenytoin ${ }^{21}$ or placebo. ${ }^{22}$ The dosage and schedule of OXC among these studies varied greatly. In these studies, OXC was initiated at a dosage of

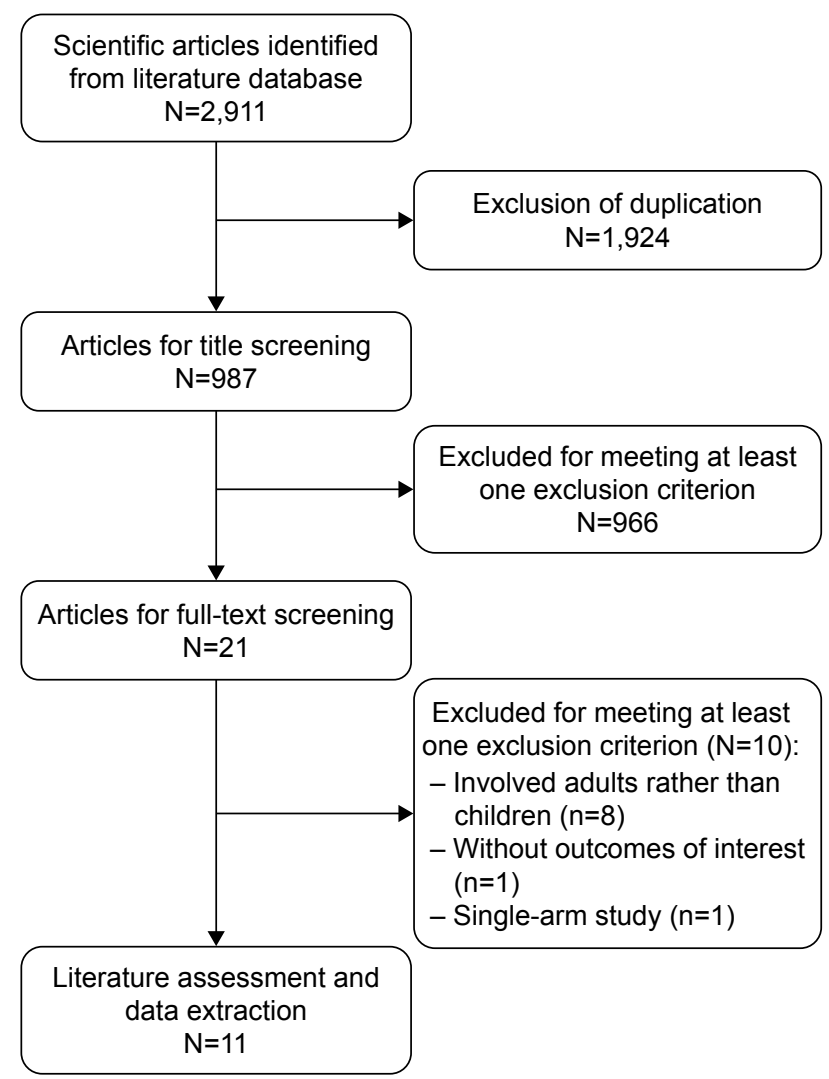

Figure I Eligibility of studies for inclusion in meta-analysis.
$5-20 \mathrm{mg} / \mathrm{kg} /$ day and was increased up to a maximum dosage of $35 \mathrm{mg} / \mathrm{kg} /$ day.

\section{Risk of bias assessment and quality of evidence}

The details of risk of bias assessment are presented in Figure 2. Of the 11 included RCTs, two ${ }^{21,22}$ were considered to be at low risk of bias, $\operatorname{six}^{23-25,28,30,31}$ at unclear risk of bias, and three ${ }^{26,27,29}$ at high risk of bias. Randomized sequence was adequately generated in four trials, ${ }^{21-23,25}$ and allocation concealment was reported in detail in two trials. ${ }^{21,23}$ The blinding of participants and personnel was described in three trials. ${ }^{21-23}$ There was no incomplete outcome data, selective reporting, or other bias in all the included studies.

The GRADE evidence profiles for these outcomes are shown in Table 2. The quality of evidence was moderate for seizure-free rate, reduction from baseline in seizure frequency, and adverse events.

\section{Seizure-free rate}

All the trials reported the data of seizure-free rate..$^{21-31}$ The seizure-free rate in the OXC and other AED group was 39.0\% and $37.7 \%$, respectively. Pooled estimates suggested that patients treated with OXC had a comparable seizure-free rate with those treated with other AEDs ( $\mathrm{RR}=1.06,95 \% \mathrm{CI}: 0.94$, $1.20 ; P=0.366$ ) (Figure 3). The test for heterogeneity was not significantly different $\left(P=0.290, I^{2}=16.1 \%\right)$.

We also conducted subgroup analysis based on the comparators, study quality, and sample size. The aggregated results showed that OXC had similar effect with phenytoin ( $\mathrm{RR}=1.01,95 \% \mathrm{CI}$ : $0.79,1.31 ; P=0.923)$, levetiracetam $(\mathrm{RR}=0.98,95 \% \mathrm{CI}: 0.84,1.14 ; P=0.786)$, sodium valproate $(\mathrm{RR}=1.27,95 \% \mathrm{CI}: 0.92,1.77 ; P=0.150)$, and placebo $(\mathrm{RR}=4.67,95 \% \mathrm{CI}: 0.55,39.47 ; P=0.157)$ in terms of seizure-free rate (Figure 3; Tables 3 and 4).

Subgroup analysis based on sample size showed that patients treated with OXC had a comparable seizure-free rate than those treated with other AEDs regardless of the sample size (for sample size $<100, \mathrm{RR}=1.04,95 \% \mathrm{CI}$ : 0.86, 1.26; $P=0.413$; for sample size $>100, \mathrm{RR}=1.07,95 \% \mathrm{CI}: 0.91$, 1.26; $P=0.685$ ) (Tables 3 and 4 ).

Subgroup analysis based on study quality showed that OXC had a similar seizure-free rate with other AEDs among the studies with low or unclear risk of bias (for studies with low risk of bias: $\mathrm{RR}=1.09,95 \% \mathrm{CI}$ : $0.84,1.41 ; P=0.507$; for studies with unclear risk of bias: $\mathrm{RR}=0.93,95 \% \mathrm{CI}$ : 0.80 , $1.09 ; P=0.374)$, whereas for the studies with high risk of 
Table I Baseline characteristics of patients in the trials included in the meta-analysis

\begin{tabular}{|c|c|c|c|c|c|c|c|}
\hline Study & Year & Country & Intervention & $\begin{array}{l}\text { Number } \\
\text { of patients }\end{array}$ & $\begin{array}{l}\text { Malel } \\
\text { female }\end{array}$ & $\begin{array}{l}\text { Age } \\
(\text { mean } \pm \text { SD, y) }\end{array}$ & $\begin{array}{l}\text { Mean duration } \\
\text { of epilepsy ( } m \text { ) }\end{array}$ \\
\hline \multirow[t]{2}{*}{ Guerreiro et $\mathrm{a}^{21}$} & 1997 & Brazil & I50 mg OXC & 97 & $46 / 51$ & $10.22(5-17)$ & NR \\
\hline & & & $50 \mathrm{mg}$ phenytoin & 96 & $50 / 46$ & $10.85(6-17)$ & NR \\
\hline \multirow[t]{2}{*}{ Glauser et $\mathrm{al}^{22}$} & 2000 & USA & $30-46 \mathrm{mg} / \mathrm{kg} / \mathrm{d}$ OXC & 138 & $51 / 49$ & II (3-17) & NR \\
\hline & & & $30-46 \mathrm{mg} / \mathrm{kg} / \mathrm{d}$ placebo & 129 & $55 / 45$ & $11(3-17)$ & NR \\
\hline \multirow[t]{2}{*}{ Coppola et $\mathrm{a}^{23}$} & 2007 & Italy & $5-20 \mathrm{mg} / \mathrm{kg} / \mathrm{d}$ OXC & 18 & $10 / 8$ & $3.3-14$ & 8.52 \\
\hline & & & $5-20 \mathrm{mg} / \mathrm{kg} / \mathrm{d}$ levetiracetam & 21 & $11 / 10$ & $3.3-14$ & 3.7 \\
\hline \multirow[t]{2}{*}{$\mathrm{Ma}^{24}$} & 2016 & People's Republic & $8-10 \mathrm{mg} / \mathrm{kg} / \mathrm{d}$ OXC & 72 & $42 / 30$ & $9 \pm 1.3$ & NR \\
\hline & & of China & $15 \mathrm{mg} / \mathrm{d}$ sodium valproate & 72 & $42 / 30$ & $10 \pm 1.1$ & NR \\
\hline \multirow[t]{2}{*}{$\operatorname{Tan}^{25}$} & 2016 & People's Republic & OXC & 54 & NR & NR & NR \\
\hline & & of China & Levetiracetam & 54 & NR & NR & NR \\
\hline \multirow[t]{2}{*}{ Wang and $\mathrm{Yu}^{26}$} & 2014 & People's Republic & $5-10 \mathrm{mg} / \mathrm{kg} / \mathrm{d} O X C$ & 21 & NR & $6.9 \pm 1.2$ & NR \\
\hline & & of China & $10-40 \mathrm{mg} / \mathrm{kg}$ sodium valproate & 21 & NR & $6.9 \pm 3.5$ & NR \\
\hline \multirow[t]{2}{*}{ Ding 27} & 2016 & People's Republic & $5-10 \mathrm{mg} / \mathrm{kg} / \mathrm{d}$ OXC & 75 & $39 / 36$ & $7.3 \pm 1.1$ & $6.0 \pm 0.9$ \\
\hline & & of China & $10-40 \mathrm{mg} / \mathrm{kg}$ sodium valproate & 75 & $38 / 37$ & $7.5 \pm 1.2$ & $5.8 \pm 0.7$ \\
\hline \multirow[t]{2}{*}{ Hou et $\mathrm{al}^{28}$} & 2015 & People's Republic & $10 \mathrm{mg} / \mathrm{kg}$ OXC & 38 & $21 / 17$ & $6.13 \pm 2.62$ & $7.34 \pm 4.22$ \\
\hline & & of China & Levetiracetam & 37 & $19 / 18$ & $6.82 \pm 3.12$ & $8.23 \pm 3.89$ \\
\hline \multirow[t]{2}{*}{ Zhang et $\mathrm{a}^{29}$} & 2015 & People's Republic & $5-10 \mathrm{mg} / \mathrm{kg} / \mathrm{d}$ OXC & 48 & NR & NR & NR \\
\hline & & of China & $10 \mathrm{mg} / \mathrm{kg} / \mathrm{d}$ levetiracetam & 41 & NR & NR & NR \\
\hline \multirow[t]{2}{*}{ Zhang ${ }^{30}$} & 2014 & People's Republic & $10 \mathrm{mg} / \mathrm{kg} / \mathrm{d}$ OXC & 32 & NR & $6.8 \pm 2.6$ & $5.8 \pm 2.2$ \\
\hline & & of China & $10 \mathrm{mg} / \mathrm{kg} / \mathrm{d}$ levetiracetam & 34 & NR & $6.8 \pm 2.6$ & $5.8 \pm 2.2$ \\
\hline \multirow[t]{2}{*}{ Chen et $\mathrm{al}^{31}$} & 2013 & People's Republic & $5-10 \mathrm{mg} / \mathrm{kg} / \mathrm{d} O X C$ & 48 & NR & $9.8 \pm 3.5$ & NR \\
\hline & & of China & $10 \mathrm{mg} / \mathrm{kg} / \mathrm{d}$ levetiracetam & 55 & NR & $9.8 \pm 3.5$ & NR \\
\hline
\end{tabular}

Abbreviations: OXC, oxcarbazepine; SD, standard deviation; NR, not reported.

bias, OXC was associated with a significantly higher seizurefree rate than other AEDs ( $R R=1.45,95 \%$ CI: 1.06, 1.99; $P=0.019$ ) (Tables 3 and 4).

\section{Reduction from baseline in seizure frequency}

Nine studies reported the data of percentage reduction from baseline in seizure frequency. ${ }^{22,24-31}$ Compared with patients treated with other AEDs, patients who had OXC experienced a comparable effect in $\geq 75 \%, 50 \%-75 \%$, or $<50 \%$ reduction from baseline in seizure frequency (for $\geq 75 \%$ reduction: $\mathrm{RR}=1.15,95 \% \mathrm{CI}: 0.88,1.49 ; P=0.310$; for 50\%-75\% reduction: $\mathrm{RR}=1.12,95 \%$ CI: $0.90,1.39$; $P=0.301$; for $<50 \%$ reduction: $\mathrm{RR}=0.79,95 \%$ CI: 0.56 , $1.12 ; P=0.179$ ) (Figures 4-6).

We conducted subgroup analysis based on the comparators. The pooled results showed that OXC resulted in a similar effect with sodium valproate $(\mathrm{RR}=1.16,95 \% \mathrm{CI}$ : $0.85,1.58 ; P=0.349)$ and levetiracetam $(\mathrm{RR}=1.12,95 \%$ CI: $0.69,1.81 ; P=0.650)$ in $\geq 75 \%$ reduction from baseline in seizure frequency (Figure 4).

OXC resulted in a similar effect with sodium valproate $(\mathrm{RR}=0.85,95 \% \mathrm{CI}: 0.59,1.22 ; P=0.372)$ and levetiracetam $(\mathrm{RR}=0.90,95 \% \mathrm{CI}: 0.61,1.34 ; P=0.617)$, but a better effect than placebo $(\mathrm{RR}=1.86,95 \% \mathrm{CI}: 1.27$,
2.74; $P=0.002)$ in $50 \%-75 \%$ reduction from baseline in seizure frequency (Figure 5).

OXC resulted in a similar effect with levetiracetam ( $\mathrm{RR}=1.00,95 \% \mathrm{CI}: 0.65,1.56 ; P=0.985)$, but an inferior effect than sodium valproate $(\mathrm{RR}=0.54,95 \% \mathrm{CI}: 0.30$, $0.96 ; P=0.0035)$ in $<50 \%$ reduction from baseline in seizure frequency (Figure 6).

Subgroup analysis based on the study quality showed that in the studies with low risk of bias, OXC was associated with a significantly better effect in 50\%-75\% reduction from baseline in seizure frequency ( $\mathrm{RR}=1.86,95 \% \mathrm{CI}: 1.27-2.74$; $P=0.002$ ) (Tables 3 and 4). For studies with high risk of bias, OXC was associated with a prior effect in $<50 \%$ reduction from baseline in seizure frequency ( $\mathrm{RR}=0.42,95 \%$ CI: $0.22-0.79 ; P=0.007$ ) (Tables 3 and 4 ).

Subgroup analysis based on the sample size showed that sample size did not affect the pooled results of OXC for $\geq 75 \%, 50 \%-75 \%$, or $<50 \%$ reduction from baseline in seizure frequency (Tables 3 and 4).

\section{Adverse events}

Ten RCTs reported the data of adverse events. ${ }^{21-23,25-31}$ The incidence of adverse events in the OXC and other AED groups was $49.2 \%$ and $47.1 \%$, respectively. The pooled estimates demonstrated that patients treated with OXC had 


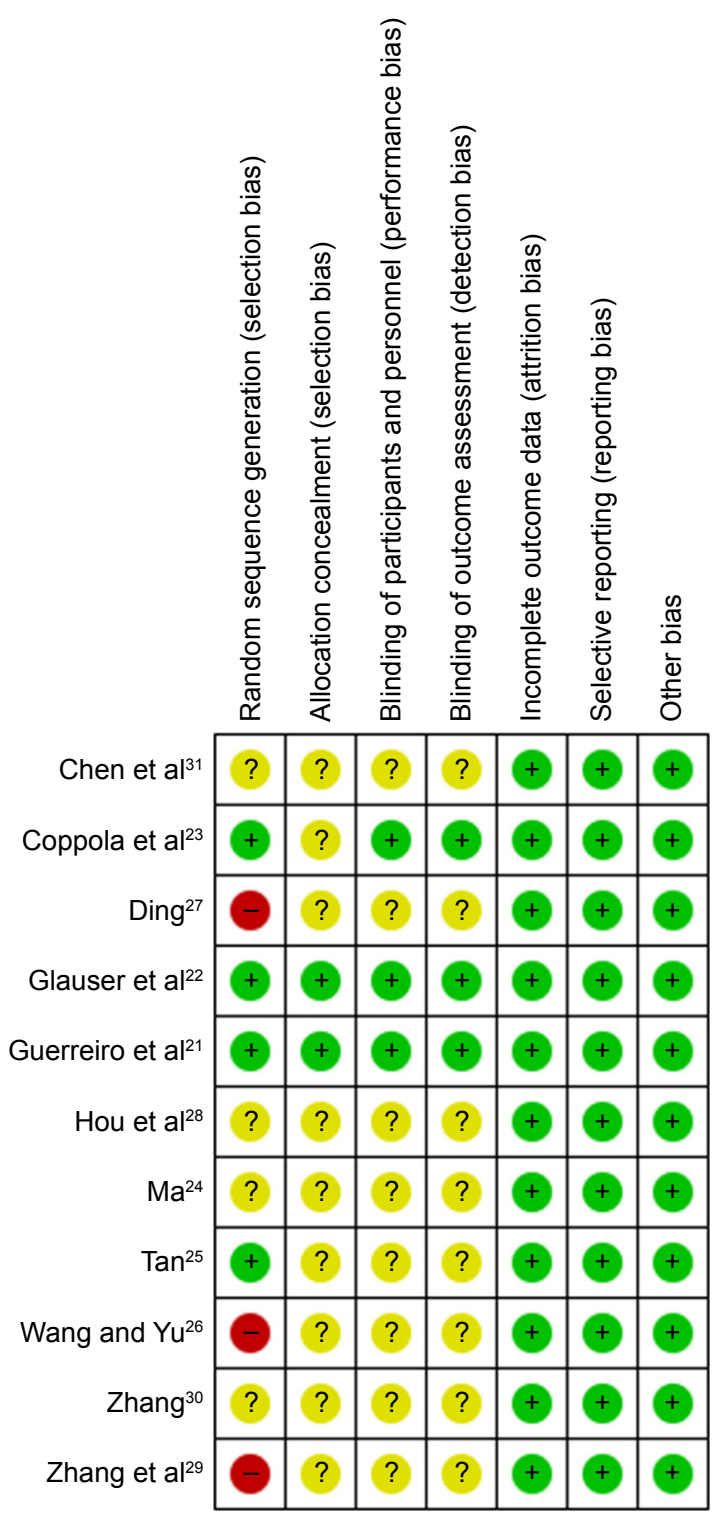

Figure 2 Risk of bias summary.

Notes: Red, high risk; blue, low risk; orange, unclear risk.

similar incidence of adverse events with those treated with other AEDs (RR $=1.01,95 \% \mathrm{CI}: 0.92,1.11 ; P=0.760)$.

\section{Publication bias}

The assessment of publication bias showed that there was no potential publication bias among the included studies (Egger's test, $P=0.27$; Begg's test, $P=0.43$ ).

\section{Discussion}

The objective of this meta-analysis was to compare the efficacy and safety of OXC with other AEDs (sodium valproate, levetiracetam, phenytoin, and placebo) in the treatment of children with epilepsy. Based on the 11 RCTs, our results showed that OXC had similar efficacy and safety as other
AEDs when treating children with epilepsy. There was no significant difference between OXC and other AEDs in terms of seizure-free rate and percentage reduction from baseline in seizure frequency. Furthermore, no significant difference in the incidence of adverse events was observed between these treatments.

There have been two published meta-analysis that compared the efficacy and safety of OXC with phenytoin/OXC in patients with epilepsy. ${ }^{32,33}$ The study conducted by Muller et $\mathrm{al}^{32}$ included two RCTs in children or adults with epilepsy. ${ }^{32}$ Based on these included studies, they found that OXC was associated with a significantly better effect than phenytoin in time to treatment withdrawal (hazard ratio $[\mathrm{HR}]=1.64,95 \%$ CI: 1.09-2.47), but similar effects in time to 12-month remission (HR $=0.92,95 \%$ CI: $0.62-1.37$ ) and time to first seizure (HR $=1.07,95 \%$ CI: 0.83-1.39). ${ }^{32}$ However, in another meta-analysis conducted by Koch et al, ${ }^{33}$ different results were observed. In that study, three RCTs that compared the efficacy and safety of OXC with carbamazepine for partial onset seizures were included. ${ }^{33}$ They observed that OXC was associated with comparable effects with carbamazepine in time to treatment withdrawal ( $\mathrm{HR}=1.04,95 \% \mathrm{CI}$ : 0.78-1.39), and treatment withdrawal for inadequate seizure control (HR $=1.33$, 95\% CI: $0.82-2.15) .{ }^{33}$ Moreover, there was no significant difference in treatment withdrawal for unacceptable side effects between the two groups ( $\mathrm{HR}=0.85,95 \%$ CI: 0.59-1.24).

Our meta-analysis expends on these two early metaanalyses to explore better characterization of evidence for OXC in children with epilepsy. 1) The present meta-analysis had a larger sample size than the previous meta-analyses, and this enhanced the statistical power to evaluate the effects of OXC. In this meta-analysis, the number of included RCTs was 11 , while for the previous ones, they were two or three, and the number of available studies for analysis was only one. 2) In this meta-analysis, we restricted study subjects to children, whereas in the previous meta-analyses, studies with both adults and children were included. The authors did not provide the data for children and adults, respectively. Thus, we are still uncertain whether OXC is effective in children or adults. 3) In the present meta-analysis, we conducted subgroup analysis based on several important factors, including comparators, study quality, and sample size. The subgroup analysis based on these factors did not significantly change the overall estimates, which added robustness to our results.

In this meta-analysis, we found that OXC had a similar effect on seizure-free rate compared with other AEDs (sodium valproate, levetiracetam, phenytoin, and placebo). 


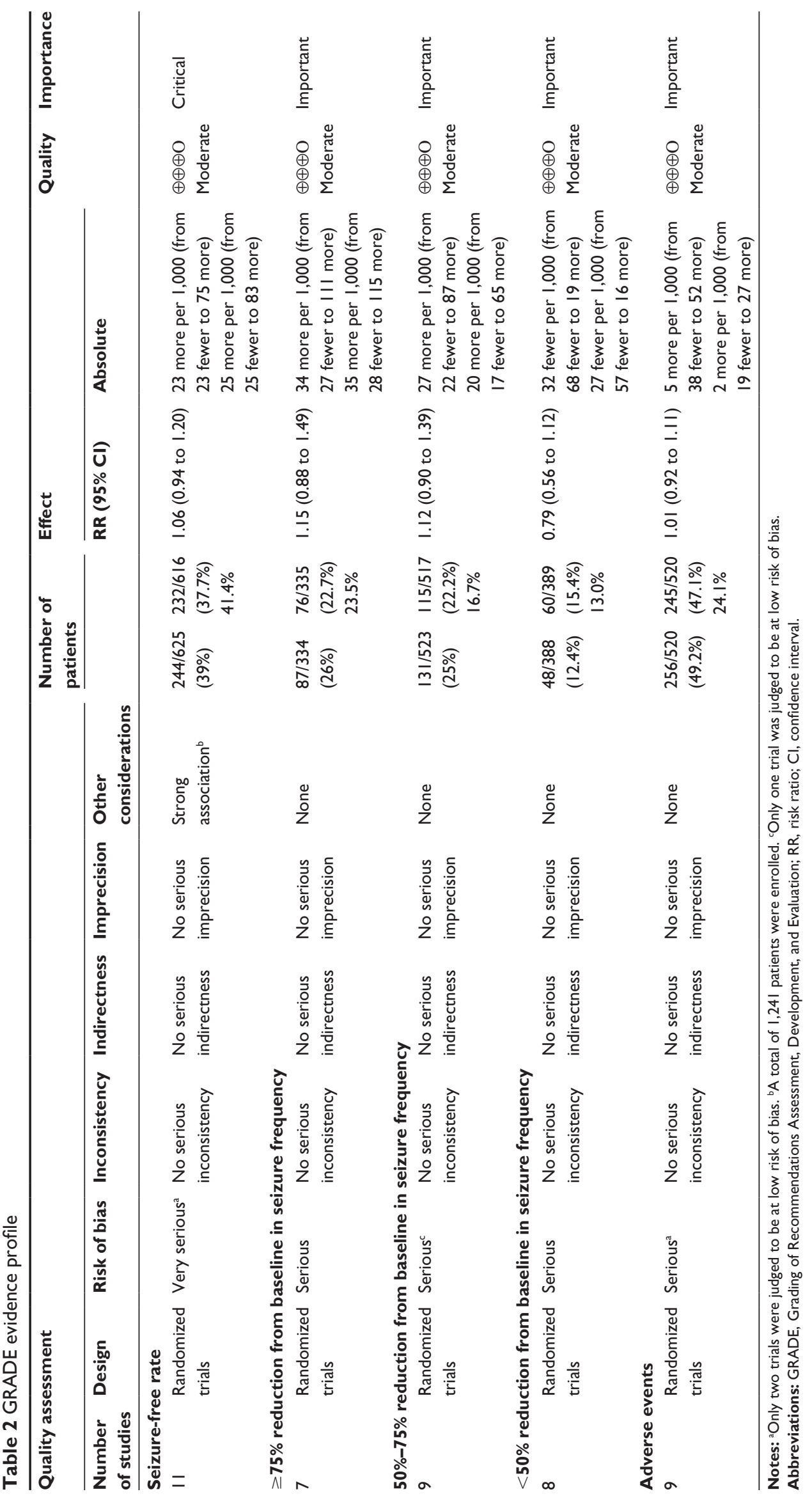




\begin{tabular}{|c|c|c|}
\hline Study ID & $\mathrm{RR}(95 \% \mathrm{Cl})$ & Weight (\%) \\
\hline \multicolumn{3}{|l|}{ Phenytoin } \\
\hline Guerreiro et al ${ }^{21}(1997)$ & $1.01(0.79,1.31)$ & 20.46 \\
\hline Subtotal $\left(I^{2}=. \%, P=.\right)$ & $1.01(0.79,1.31)$ & 20.46 \\
\hline \multicolumn{3}{|l|}{ Placebo } \\
\hline Glauser et $\mathrm{al}^{22}(2000)$ & $4.67(0.55,39.47)$ & 0.45 \\
\hline \multicolumn{3}{|c|}{$4.67(0.55,39.47) \quad 0.45$} \\
\hline \multicolumn{3}{|l|}{ Levetiracetam } \\
\hline Coppola et $\mathrm{al}^{23}(2007)$ & $0.80(0.58,1.10)$ & 7.61 \\
\hline $\operatorname{Tan}^{25}(2016)$ & $0.93(0.64,1.35)$ & 12.15 \\
\hline Hou et $\mathrm{al}^{28}(2015)$ & $0.90(0.65,1.24)$ & 11.43 \\
\hline Zhang et $\mathrm{al}^{29}(2015)$ & $1.21(0.76,1.91)$ & 7.96 \\
\hline Zhang $^{30}(2014)$ & $1.14(0.66,1.96)$ & 5.89 \\
\hline Chen et $\mathrm{al}^{31}(2013)$ & $0.99(0.75,1.30)$ & 14.96 \\
\hline Subtotal $\left(I^{2}=0.0 \%, P=0.697\right)$ & $0.98(0.84,1.14)$ & 60.00 \\
\hline \multicolumn{3}{|l|}{ Sodium valproate } \\
\hline $\mathrm{Ma}^{24}(2016)$ & $0.86(0.50,1.47)$ & 9.11 \\
\hline Wang and $\mathrm{Yu}^{26}(2014)$ & $1.44(0.80,2.62)$ & 3.90 \\
\hline $\operatorname{Ding}^{27}(2016)$ & $1.79(1.01,3.16)$ & 6.07 \\
\hline Subtotal $\left(I^{2}=44.4 \%, P=0.165\right)$ & $1.27(0.92,1.77)$ & 19.09 \\
\hline Overall $\left(I^{2}=16.1 \%, P=0.290\right)$ & $1.06(0.94,1.20)$ & 100 \\
\hline $\begin{array}{c}1 \\
0.0253\end{array}$ & & \\
\hline
\end{tabular}

Figure 3 Forest plot showing the effects of OXC on seizure-free rate.

Abbreviations: $\mathrm{Cl}$, confidence interval; $\mathrm{RR}$, risk ratio; OXC, oxacarbazepine.

Our result is comparable to data from some other studies. In the trial of Coppola et al, ${ }^{23}$ children with newly diagnosed benign epilepsy with centrotemporal spike were randomized to receive $\mathrm{OXC}$ or levetiracetam. ${ }^{23}$ At a mean follow-up period of 18.5 months, 13 out of $18(72.2 \%)$ children in the OXC group and 19 out of $21(90.5 \%)$ in the levetiracetam group had no further seizures. ${ }^{23}$ Although the seizure-free rate in levetiracetam group seemed to be higher than that in OXC group, the difference between them was not statistically significant $(P=0.41) .{ }^{23}$ Similarly, in another double-blind, randomized trial, no significant difference in seizure-free rate was observed between OXC and phenytoin. ${ }^{21}$ In that study,
193 children with either secondarily generalized seizures or GTCS without partial onset were enrolled. ${ }^{21}$ During the maintenance period, $61 \%$ of children in the OXC group and $60 \%$ of children in phenytoin group were seizure free, ${ }^{21}$ which indicated that $\mathrm{OXC}$ had a similar effect with phenytoin in making patients seizure free.

Assessment of the percentage reduction from baseline in seizure frequency also suggested a similar effect with $\mathrm{OXC}$ compared with other antiepileptic drugs (sodium valproate, levetiracetam, and placebo). Seventeen percentage of patients treated with OXC experienced $\mathrm{a} \geq 75 \%$ reduction from baseline in seizure frequency compared with $16.0 \%$ of patients

Table 3 Summary of the risk ratios with $95 \%$ confidence intervals of outcomes in the subgroup analysis

\begin{tabular}{|c|c|c|c|c|}
\hline \multirow[t]{2}{*}{ Outcomes } & \multicolumn{4}{|l|}{ Comparators } \\
\hline & Phenytoin & Levetiracetam & Sodium valproate & Placebo \\
\hline Seizure-free rate & I.0I $(0.79-\mid .31)$ & $0.98(0.84-1.14)$ & $1.27(0.92-1.77)$ & $4.67(0.55-39.47)$ \\
\hline$\geq 75 \%$ reduction from baseline in seizure frequency & - & $1.12(0.69-1.81)$ & $1.16(0.85-1.58)$ & - \\
\hline $50 \%-75 \%$ reduction from baseline in seizure frequency & - & $0.90(0.6 \mathrm{I}-\mathrm{I} .34)$ & $0.85(0.59-1.22)$ & $1.86(1.27-2.74)$ \\
\hline$<50 \%$ reduction from baseline in seizure frequency & - & $1.00(0.65-1.56)$ & $0.54(0.30-0.96)$ & - \\
\hline
\end{tabular}


Table 4 Summary of the risk ratios with $95 \%$ confidence intervals of outcomes in the subgroup analysis based on study design and sample size

\begin{tabular}{|c|c|c|c|c|c|}
\hline \multirow[t]{2}{*}{ Outcomes } & \multicolumn{3}{|l|}{ Study quality } & \multicolumn{2}{|l|}{ Sample size } \\
\hline & $\begin{array}{l}\text { Low risk of } \\
\text { bias }\end{array}$ & $\begin{array}{l}\text { Unclear risk } \\
\text { of bias }\end{array}$ & $\begin{array}{l}\text { High risk of } \\
\text { bias }\end{array}$ & $\geq 100$ & $<100$ \\
\hline Seizure-free rate & $\mathrm{I} .09(0.84-\mathrm{I} .4 \mathrm{I})$ & $0.93(0.80-1.09)$ & $1.45(1.06-1.99)$ & $1.07(0.91-1.26)$ & $1.04(0.86-1.26)$ \\
\hline$\geq 75 \%$ reduction from baseline in seizure frequency & - & $1.12(0.79-1.59)$ & $1.18(0.79-1.76)$ & $1.22(0.89-1.65)$ & $1.01(0.6 \mathrm{I}-\mathrm{I} .65)$ \\
\hline $50 \%-75 \%$ reduction from baseline in seizure frequency & $1.86(1.27-2.74)$ & $0.96(0.67-1.37)$ & $0.77(0.52-1.15)$ & $1.05(0.67-1.64)$ & $0.97(0.53-1.77)$ \\
\hline$<50 \%$ reduction from baseline in seizure frequency & - & $1.09(0.70-1.67)$ & $0.42(0.22-0.79)$ & $0.82(0.52-1.29)$ & $0.74(0.43-1.27)$ \\
\hline
\end{tabular}

treated with levetiracetam $(\mathrm{RR}=1.12,95 \% \mathrm{CI}: 0.69,1.81$; $P=0.650$ ). Similarly, in comparison with sodium valproate, $\mathrm{OXC}$ also resulted in a comparable effect. The percentage of patients who had a $\geq 75 \%$ reduction from baseline in seizure frequency in the $\mathrm{OXC}$ and sodium valproate groups was $34.5 \%$ and $29.8 \%$, respectively. However, OXC showed a statistically significant improvement in reduction from baseline in seizure frequency as compared with placebo. In the trial of Glauser et al, ${ }^{22} 41 \%$ of patients in the OXC group developed a $>50 \%$ reduction from baseline in partial seizure frequency per 28 days compared with $22 \%$ of patients in the placebo group. ${ }^{22}$ These results demonstrated that OXC did not have superior effects than sodium valproate or levetiracetam in the reduction of seizure frequency.

Regarding the safety profile, the incidence of adverse events was almost similar between the OXC and other
AED groups. The most common adverse events for OXC included nausea, vomiting, and rash, which would lead to discontinuation of therapy. Hyponatremia has been reported to be associated with OXC use. ${ }^{31-34}$ Children treated with $\mathrm{OXC}$ were less likely to develop hyponatremia than adults. ${ }^{35}$ This finding was confirmed in the multicenter, randomized, placebo-controlled trial conducted by Glauser et al. ${ }^{22}$ In that trial, no hyponatremia was observed in the pediatric patients. ${ }^{22}$ According to the previous report, hyponatremia usually appears in the first 3 months of treatment; ${ }^{34}$ thus the 4 -month phase in the Glauser's study was long enough to assess the emergence of hyponatremia.

There have been several potential limitations in this meta-analysis that should be considered. 1) Our study included 11 RCTs, and some of the included studies had a

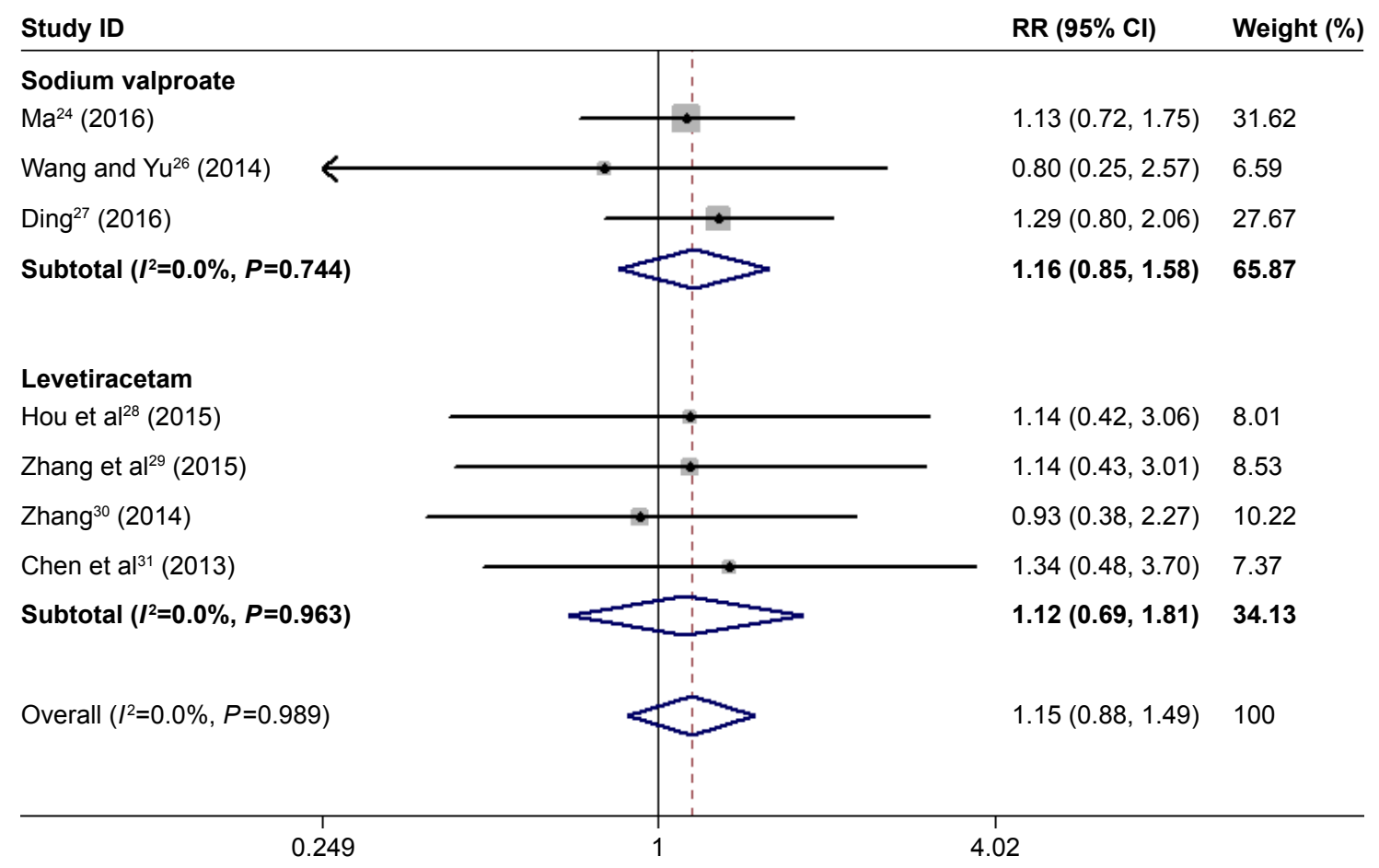

Figure 4 Forest plot showing the effects of $O X C$ on $\geq 75 \%$ reduction from baseline in seizure frequency. Abbreviations: $\mathrm{Cl}$, confidence interval; $\mathrm{RR}$, risk ratio; OXC, oxacarbazepine. 


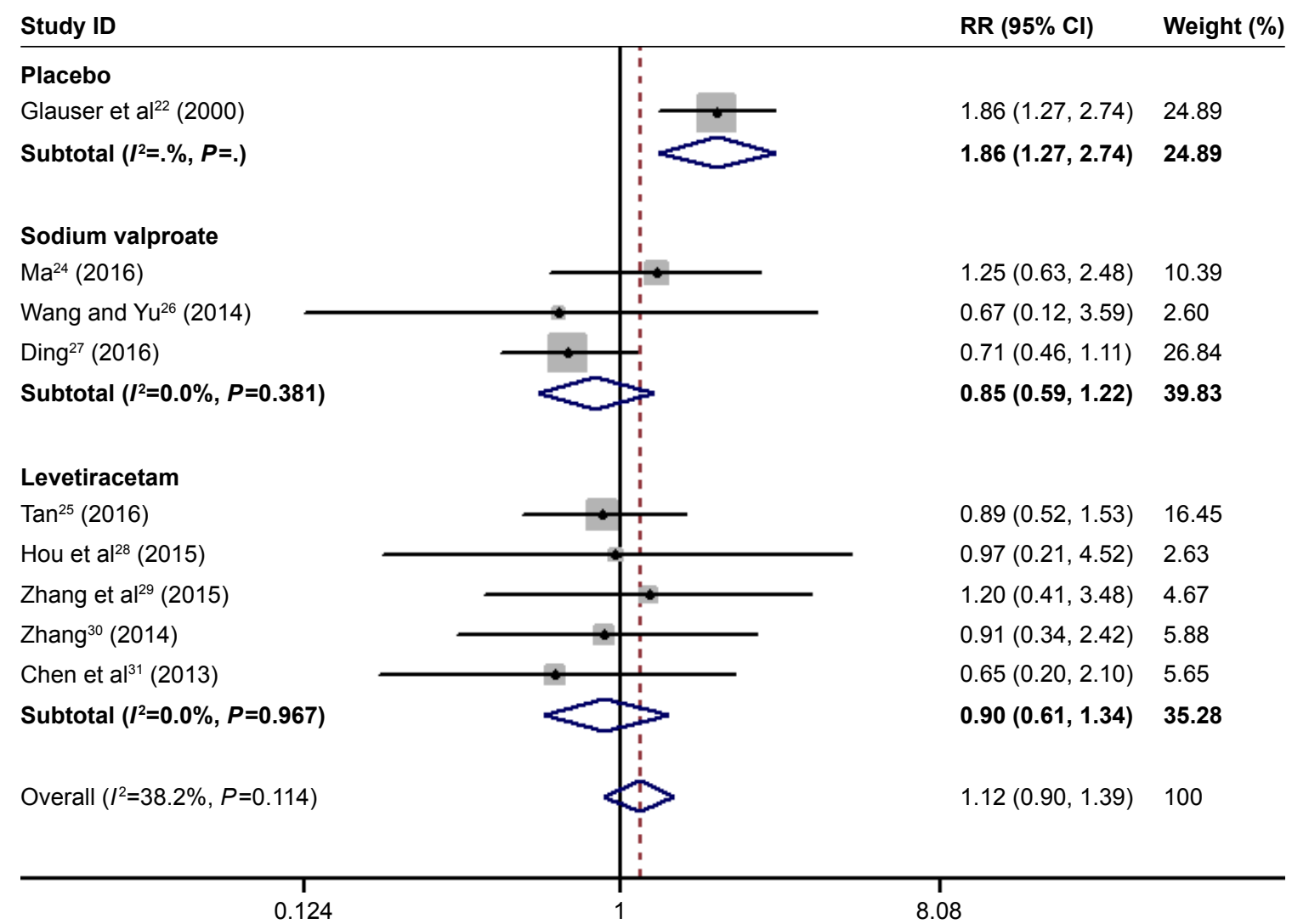

Figure 5 Forest plot showing the effects of OXC on $50 \%-75 \%$ reduction from baseline in seizure frequency. Abbreviations: $\mathrm{Cl}$, confidence interval; $\mathrm{RR}$, risk ratio; OXC, oxacarbazepine.

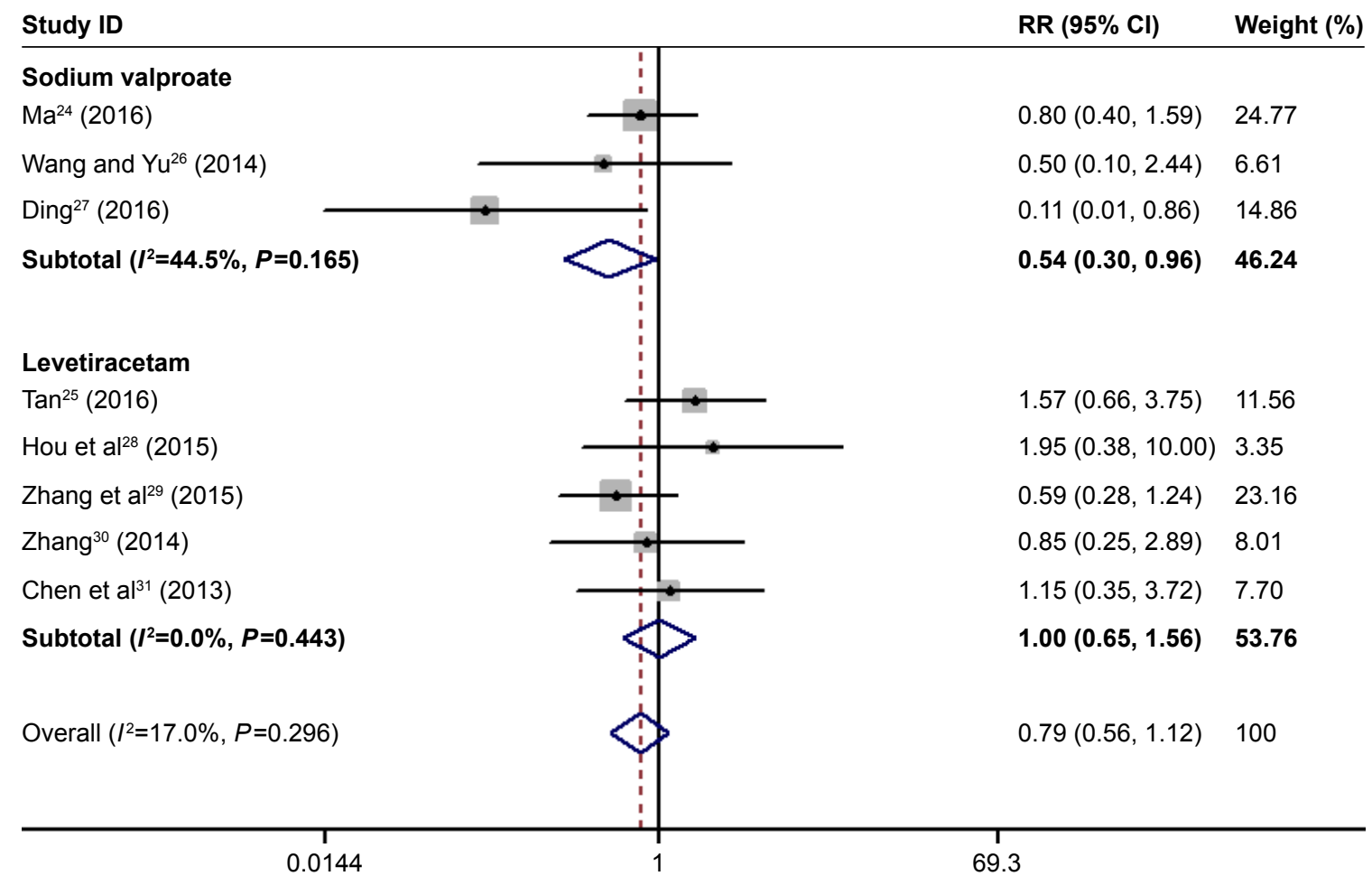

Figure 6 Forest plot showing the effects of OXC on $<50 \%$ reduction from baseline in seizure frequency. Abbreviations: $\mathrm{Cl}$, confidence interval; $\mathrm{RR}$, risk ratio; OXC, oxacarbazepine. 
relatively small sample size. Small trials are more likely to result in an overestimate of the treatment effects compared with larger trials. 2) There was substantial heterogeneity among the included studies. However, one should not be surprised when considering the differences in dosage of OXC, treatment schedule, treatment controls, the types of epilepsy, and study quality. These factors have a potential impact on the pooled estimates. 3) Due to the sparse reporting among the included studies, we did not assess the effects and safety of OXC in different types of epilepsy. Further large-scale RCTs are needed to investigate the effects of OXC in different types of epilepsy. 4) Most of the included studies were from Chinese publications. Although no potential publication bias was identified among the included studies, we could not exclude the possibility that our results were biased by these Chinese studies. Thus, physicians should be with caution when applying these findings into clinical practices.

\section{Conclusion}

In conclusion, this meta-analysis suggested that $\mathrm{OXC}$ had similar seizure-free rate and percentage reduction from baseline in seizure frequency as other AEDs in children with epilepsy. Moreover, OXC also induced a similar incidence of adverse events with other AEDs. However, considering the limitations of this meta-analysis, large-scale RCTs are needed to verify our findings and investigate the effects of $\mathrm{OXC}$ in children with different types of epilepsy.

\section{Disclosure}

The authors report no conflicts of interest in this work.

\section{References}

1. Bourgeois BF. Drug treatment of benign focal epilepsies of childhood. Epilepsia. 2000;41(8):1057-1058.

2. Carrozzino D, Marchetti D, Laino D, et al. Anxiety in adolescent epilepsy. A clinimetric analysis. Nord J Psychiatry. 2016;70(6):424-429.

3. Verrotti A, Carrozzino D, Milioni M, Minna M, Fulcheri M. Epilepsy and its main psychiatric comorbidities in adults and children. $J$ Neurol Sci. 2014;343(1-2):23-29.

4. Saconato H, Prado GF, Puga ME, Atallah AN. Oxcarbazepine for refractory epilepsy: systematic review of the literature. Sao Paulo Med J. 2009; 127(3):150-159.

5. Pellock JM. Utilization of new antiepileptic drugs in children. Epilepsia. 1996;37(Suppl 1):S66-S73.

6. Tzitiridou M, Panou T, Ramantani G, Kambas A, Spyroglou K, Panteliadis C. Oxcarbazepine monotherapy in benign childhood epilepsy with centrotemporal spikes: a clinical and cognitive evaluation. Epilepsy Behav. 2005;7(3):458-467.

7. French JA, Kanner AM, Bautista J, et al. Efficacy and tolerability of the new antiepileptic drugs I: treatment of new onset epilepsy: report of the Therapeutics and Technology Assessment Subcommittee and Quality Standards Subcommittee of the American Academy of Neurology and the American Epilepsy Society. Neurology. 2004;62(8):1252-1260.
8. French JA, Kanner AM, Bautista J, et al. Efficacy and tolerability of the new antiepileptic drugs II: treatment of refractory epilepsy: report of the Therapeutics and Technology Assessment Subcommittee and Quality Standards Subcommittee of the American Academy of Neurology and the American Epilepsy Society. Neurology. 2004;62(8):1261-1273.

9. Sabers A, Gram L. Oxcarbazepine. In: Trimble MR, editor. New Anticonvulsants: Advances in the Treatment of Epilepsy. West Sussex, UK: John Wiley \& Sons Ltd; 1994:103-112.

10. Dam M, Ekberg R, Loyning Y, Waltimo O, Jakobsen K. A double-blind study comparing oxcarbazepine and carbamazepine in patients with newly diagnosed, previously untreated epilepsy. Epilepsy Res. 1989; 3(1):70-76.

11. McKee PJ, Blacklaw J, Forrest G, et al. A double-blind, placebocontrolled interaction study between oxcarbazepine and carbamazepine, sodium valproate and phenytoin in epileptic patients. Br J Clin Pharmacol. 1994;37(1):27-32.

12. Bill PA, Vigonius U, Pohlmann H, et al. A double-blind controlled clinical trial of oxcarbazepine versus phenytoin in adults with previously untreated epilepsy. Epilepsy Res. 1997;27(3):195-204.

13. Moher D, Liberati A, Tetzlaff J, Altman DG. Preferred reporting items for systematic reviews and meta-analyses: the PRISMA statement. $B M J$. 2009;339:b2535.

14. Higgins JP, Altman DG, Gotzsche PC, et al. The Cochrane Collaboration's tool for assessing risk of bias in randomised trials. $B M J$. 2011;343:d5928.

15. Guyatt GH, Oxman AD, Vist GE, et al. GRADE: an emerging consensus on rating quality of evidence and strength of recommendations. $B M J$. 2008;336(7650):924-926.

16. Higgins JP, Thompson SG, Deeks JJ, Altman DG. Measuring inconsistency in meta-analyses. BMJ. 2003;327(7414):557-560.

17. DerSimonian R, Laird N. Meta-analysis in clinical trials. Control Clin Trials. 1986;7(3):177-188.

18. Mantel N, Haenszel W. Statistical aspects of the analysis of data from retrospective studies of disease. J Natl Cancer Inst. 1959;22(4): 719-748.

19. Begg CB, Mazumdar M. Operating characteristics of a rank correlation test for publication bias. Biometrics. 1994;50(4):1088-1101.

20. Egger M, Davey Smith G, Schneider M, Minder C. Bias in meta-analysis detected by a simple, graphical test. BMJ. 1997;315(7109):629-634.

21. Guerreiro MM, Vigonius U, Pohlmann H, et al. A double-blind controlled clinical trial of oxcarbazepine versus phenytoin in children and adolescents with epilepsy. Epilepsy Res. 1997;27(3):205-213.

22. Glauser TA, Nigro M, Sachdeo R, et al. Adjunctive therapy with oxcarbazepine in children with partial seizures. The Oxcarbazepine Pediatric Study Group. Neurology. 2000;54(12):2237-2244.

23. Coppola G, Franzoni E, Verrotti A, et al. Levetiracetam or oxcarbazepine as monotherapy in newly diagnosed benign epilepsy of childhood with centrotemporal spikes (BECTS): an open-label, parallel group trial. Brain Dev. 2007;29(5):281-284.

24. Ma J. Analysis of clinical curative effect of single medicine of oxcarbazepine in treatment of children temporal epilepsy. China Foreign Med Treat. 2016;9:106-107.

25. Tan J. Comparison on Efficacy of Oxcarbazepine and Levetiracetam Monotherapy in Treatment of Benign Epilepsy Children with Centrotemporal Spikes. Evaluation and analysis of drug-use in hospitals of China. 2016;16:348-350.

26. Wang F, Yu J. Therapeutic effects of oxcarbazepine in children with partial seizures of epilepsy. Lab Med Clin. 2014;11(4):450-452.

27. Ding Y. Clinical effects of oxcarbazepine in the treatment of children with partial seizures. J China Prescription Drug. 2016;14(6):79.

28. Hou Y, Ouyang J, You W, Yang H, Liu B, Zhong J. Effect of oxcarbazepine and levetiracetam on epilepsy children with newly diagnosed partial seizure. Pract Pharm Clin Remedies. 2015;18(2):160-164.

29. Zhang S, Jin C, Zhang J. Clinical effects of levetiracetam and oxcarbazepine for children with partial onset seizures and the impacts on electroencephalogram. Matern Child Health Care China. 2015;30: 5679-5681. 
30. Zhang M. Efficacy and safety of levetiracetam and oxcarbazepine monotherapy on children with epilepsy newly diagnosed partial seizure. Strait Pharm J. 2014;26(12):95-97.

31. Chen T, Guo Q, Yang Y. Efficacy comparison of levetiracetam and oxcarbazepine monotherapy on children epilepsy. Chongqing Med. 2013; 42(16):1826-1827.

32. Muller M, Marson AG, Williamson PR. Oxcarbazepine versus phenytoin monotherapy for epilepsy. Cochrane Database Syst Rev. 2006; (2):Cd003615.
33. Koch MW, Polman SK. Oxcarbazepine versus carbamazepine monotherapy for partial onset seizures. Cochrane Database Syst Rev. 2009; (4):Cd006453.

34. Trileptal (oxcarbazepine) tablets [prescribing information]. East Hanover, NJ: Novartis Pharmaceuticals Corp, 2000.

35. Sachdeo R, Wasserstein A, Mesenbrink P, D'Souza J. Oxcarbazepine (Trileptal) effect on serum sodium. Poster presented at: 53rd Annual Meeting of the American Epilepsy Society; December 7, 1999; Orlando, FL.

\section{Publish your work in this journal}

Neuropsychiatric Disease and Treatment is an international, peerreviewed journal of clinical therapeutics and pharmacology focusing on concise rapid reporting of clinical or pre-clinical studies on a range of neuropsychiatric and neurological disorders. This journal is indexed on PubMed Central, the 'PsycINFO' database and CAS, and is the official journal of The International Neuropsychiatric Association (INA). The manuscript management system is completely online and includes a very quick and fair peer-review system, which is all easy to use. Visit http://www.dovepress.com/testimonials.php to read real quotes from published authors.

Submit your manuscript here: http://www.dovepress.com/neuropsychiatric-disease-and-treatment-journal 